Int. J. Electrochem. Sci., 14 (2019) 5831 - 5845

International Journal of

ELECTROCHEMICAL

SCIENCE

$\underline{\text { www.electrochemsci.org }}$

\title{
Synergetic Protection Hollow Silicon by Nitrogen-Doped Carbon/Reduced Graphene Oxide to Improve the Electrochemical Stability as Lithium-Ion Battery Anode
}

\author{
Yan Ma ${ }^{1}$, Yunxia Liu ${ }^{1}$, Mingshan Wang ${ }^{1, *}$, Zhenliang Yang ${ }^{2}$, Yongshun Bai ${ }^{1}$, Xue Yin ${ }^{l}$, Chun Luo ${ }^{1}$, \\ Yun Huang ${ }^{l}$, Xing $\mathrm{Li}^{1, *}$ \\ ${ }^{1}$ The Center of New Energy Materials and Technology, School of Materials Science and Engineering, \\ Southwest Petroleum University, Chengdu, Sichuan 610500, P.R. China \\ ${ }^{2}$ Institute of Materials, China Academy of Engineering Physics, Mianyang, Sichuan 621908, PR \\ China \\ *E-mail: wangmingshan@ @ swpu.edu.cn, lixing@ @ swpu.edu.cn
}

doi: $10.20964 / 2019.06 .77$

Received: 5 March 2019 / Accepted: 12 April 2019 / Published: 10 May 2019

Silicon is the most sought-after candidates for next-generation electrode materials for high energy density lithium ion battery because of its high theoretical capacity and appropriate working potential. However, it still suffers from dramatic volume expansion/shrinkage during repeat discharge/charge process, along with unstable solid electrolyte interface films, which largely degrade its practical application. To overcome these problems, we present an approach to synthesize hollow silicon@nitrogen-doped carbon/reduced graphene oxide (H-Si@N-C/rGO) composite via polymerization coating with dopamine on hollow Si and hydrothermal with graphene oxide followed by thermal reduction. The hollow structure of $\mathrm{Si}$ and intragranular voids between the Si nanoparticles significantly relief the volume change during lithiation/delithiation process. The synergetic protecting of nitrogen-doped carbon/reduced graphene oxide also improves the stability of surface of silicon. As a result, the H-Si@ N-C/rGO composite delivers initial reversible capacity of $818 \mathrm{mAh} \mathrm{g}^{-1}$ with retains $92 \%$ of initial capacity after 100 cycles at a current density of $0.2 \mathrm{~A} \mathrm{~g}^{-1}$, and also displays stable cycling performance at a high current density of $1 \mathrm{~A} \mathrm{~g}^{-1}$.

Keywords: Hollow silicon; Dopamine; Graphene; Lithium ion battery anode

\section{$\underline{\text { FULL TEXT }}$}

(C) 2019 The Authors. Published by ESG (www.electrochemsci.org). This article is an open access article distributed under the terms and conditions of the Creative Commons Attribution license (http://creativecommons.org/licenses/by/4.0/). 